\section{¿QUÉ ES LA HISTORIA CULTURAL DE LA CIENCIA?}

\author{
Juan Pimentel \\ Instituto de Historia \\ Centro de Ciencias Humanas y Sociales, CSIC \\ c/ Albasanz, 26-28 \\ 28037 Madrid
}

\begin{abstract}
This essay examines what the cultural history of science is, and points out some of the problems with regard to its correct definition and demarcation. It emphasizes some key concepts (practices and representations) and some significant approaches (the visual, the material, the symbolic) in the development of this line of inquiry that may contribute to our understanding of science as culture.
\end{abstract}

KEY WORDS: Cultural history of science; practices; representations; material culture; visual culture.

Para hablar del significado y el lugar de la historia cultural de la ciencia quizás no esté de más comenzar por la pregunta preliminar: ¿Existe, es reconocible e identificable una historia cultural de la ciencia? ¿Se trata de una rúbrica à la page, otro modismo pasajero, la penúltima sutileza escolástica con que se trata de relanzar una disciplina algo marginal como es la historia de la ciencia? ¿0 por el contrario es una categoría útil que recoge el pulso más actual de uno de los subgéneros historiográficos más innovadores de los últimos tiempos?

\section{El doble VínCULO Y LA REDUNDANCIA}

Vaya por delante que quizás para algunos la fórmula "historia cultural de la ciencia" entrañe algo parecido a una doble constricción, un doble requerimiento o doble vínculo, a double bind, como se dice en inglés, una expresión -dicho sea de paso- acuñada por el antropólogo Gregory Bateson en el ámbito de la psiquiatría terapéutica para referirse a una información paradójica o esquizofrénica, donde una parte del mensaje niega y contradice otra parte del mismo mensaje'.

En efecto, quienes lo entienden así dan por hecha una suerte de oposición entre ciencia y cultura, una relación paradójica o esquizofrénica entre ambas, lo que en cierto

\section{WHAT IS THE CULTURAL HISTORY OF SCIENCE?}

RESUMEN: Este ensayo trata de explicar qué es la historia cultural de la ciencia y apunta algunos de los problemas para su correcta definición y demarcación. Destaca algunos términos clave (prácticas y representaciones) y algunas orientaciones significativas (lo visual, lo material, lo simbólico) en el desarrollo de un área de estudios que puede contribuir a entender la ciencia como cultura.

PALABRAS CLAVE: Historia cultural de la ciencia; prácticas; representaciones; cultura material; cultura visual.

sentido es una reminiscencia de la versión popular de la dialéctica entre las dos culturas, originada en la conferencia que dictó Charles P. Snow en el Senate House de Cambridge en $1959^{2}$. Pese a que la polémica entre Snow y C.R. Leavis entrañaba una consideración de la ciencia como cultura, incluso en medios académicos son numerosos quienes todavia presuponen que ciencia y cultura ocupan hemisferios opuestos del conocimiento: uno habitado por la racionalidad, la objetividad, el método y el conocimiento de la naturaleza; el otro por aspectos vinculados a lo subjetivo, lo afectivo y lo creativo, a las artes y las letras. El propio Snow daba carta de naturaleza a esta visión, cuando arrancaba su famoso texto con una confesión francamente reveladora: "Por formación yo era científico; por vocación, escritor". Es un lugar común: una cosa es el mundo del conocimiento, asociado al método, la pedagogía, al logos y a lo público; otra bien distinta el de las artes y las letras, donde adquieren desarrollo aspectos más creativos y afectivos de la personalidad humana, un espacio donde cobran vida el pathos y lo privado. El lenguaje sanciona esta economía binaria: los científicos conocen o descubren; los artistas crean o transmiten emociones; la ciencia transcribe el mundo, la cultura lo recrea.

Es preciso dejarlo muy claro: quienes piensan así, creen que detrás de la fórmula historia cultural de la ciencia se 
tratan los aspectos culturales de la ciencia, es decir, los que no son científicos estrictamente hablando, una afirmación que niega la mayor, esto es, que la ciencia es cultura.

Esa forma de entender las cosas vendría a reproducir otro esquema antiguo, el que oponía a internalistas y externalistas en la historia de la ciencia de mediados del siglo pasado, la clásica dialéctica de la época de la Guerra Fría, como ha señalado Peter Gallison en un artículo reciente ${ }^{3}$. Desde esta perspectiva -que aquí estamos caricaturizando, obviamente- los historiadores culturales de la ciencia de ahora -huelga decir- se corresponderían con los externalistas de entonces. Esta visión, finalmente, reproduciría la propia oposición entre naturaleza y cultura. Mientras que por ciencia entendemos el conocimiento de la naturaleza, la expresión historia cultural de la ciencia vendría a recordar cuánto de artificial o de humano hay en este conocimiento de la naturaleza.

Así las cosas, resulta explicable que otros muchos, entre los cuales me encuentro, tengamos ideas encontradas (y hasta sentimientos ambivalentes) respecto a la expresión. Guardamos ciertos recelos, lo que resulta paradójico en cierto modo, pues somos considerados historiadores culturales de la ciencia, incluso damos por buena la etiqueta, y sin embargo discrepamos de la forma de entender las cosas recién descrita y advertimos el pleonasmo, la redundancia innecesaria que anida bajo la fórmula historia cultural de la ciencia. Toda historia, por definición, es historia cultural, en la medida en que toda expresión o manifestación de la actividad humana es culturalmente significativa o está instalada en una trama que puede ser leída en términos culturales. Desde el momento en que aceptamos que la cultura (sea cuál sea la acepción de un término elusivo pero no por ello prescindible) viene a ser, como se ha dicho a menudo, la naturaleza del ser humano (no importa si la consideramos primera o segunda naturaleza), habremos de inferir que todo relato histórico recoge o reconstruye, explícita o implícitamente, de manera más diáfana, consciente o todo lo contario, elementos y perfiles de las formas y los significados con que las distintas sociedades o grupos humanos emprenden cualquier actividad.

Todo hecho científico, toda teoría o toda práctica relacionada con el conocimiento de la naturaleza es un hecho profundamente cultural. Tal y como también es un hecho social. Podriamos tomar el dictum de Bruno Latour ("hay tanta ciencia fuera como dentro del laboratorio y tanta sociedad fuera como en su seno") y canjear el término cultura por sociedad. En ambas fórmulas se deshace el antiguo binomio internalismo/externalismo y se pone de manifiesto que hablar de historia social o cultural de la ciencia viene a redundar sobre cosas -esta vez sí- que deberíamos dar por supuestas y que quizás no sería necesario enfatizar o subrayar. ¿Por qué se hace entonces?

\section{UNA DISCIPLINA REORIENTADA}

Lo cierto es que también se habla de historia cultural de la ciencia de manera justificada por el giro culturalista que ha experimentado la historiografía en términos generales, así como por el propio desarrollo de la historia de la ciencia en los últimos veinte años, una disciplina que venía de una tradición muy vinculada a la historia de las ideas. Se trataba de un relato que había hecho de la ciencia (y en concreto de la ciencia moderna occidental) una epopeya del pensamiento, una cruzada liberadora de la razón contra la superstición y la ignorancia, en fin, la aventura por antonomasia del género humano (una gesta paradójicamente $\sin$ hechos físicos, sino intelectuales).

Fijémonos en aquella historia de la ciencia moderna elaborada entre 1920 y 1970, la Ilamada gran tradición que hunde sus raices en figuras como Herbert Butterfield, que conecta precisamente con la historia de las ideas de la Johns Hopkins (Lovejoy, Marjorie Hope Nicholson) y que se despliega con propiedad con el gran fresco de la Revolución Científica trazado por Westfall, Bernard Cohen, A.R. Hall o Koyré4.

Era un formato historiográfico característico de una gran narrativa, centrado en ciertos héroes del pensamiento y en sus textos, una historia hecha de descubrimientos, teorías, ideas y palabras. Su inconfundible aliento neoilustrado convertía los hechos del pasado en un relato ascendente y progresivo de carácter emancipador. Reproducía el irremediable ascenso y la difusión de las luces.

Frente a dicho formato surgieron nuevas propuestas de entender y practicar la disciplina desde mediados de la década de 1980, algunas de las cuales han terminado por ser calificadas como historia cultural de la ciencia, un 
hecho que sin duda obedece al doble influjo de la historia cultural y los estudios culturales -dos campos muy diferentes- y que sin embargo tiende a esconder o a maquillar un dato fundamental: que el énfasis sobre la dimensión cultural en los estudios históricos de la ciencia se debió en un primer momento y fundamentalmente al impacto de los SSK (estudios sociológicos del conocimiento científico), al doble giro antropológico, pero también sociológico que experimentó la historia de la ciencia como disciplina ${ }^{5}$.

Así tenemos, por chocante que pueda parecer, que cuando se habla de historia cultural de la ciencia se está haciendo referencia a un dominio ciertamente difuso donde confluye una amalgama de miradas alternativas a la historia de la ciencia more tradicional (vinculada a la historia intelectual y de las ideas), marcadas en cierto modo por los SSK, aunque también -como es lógico- por la antropología, los estudios culturales y la propia historia cultural (Dear, 1995, 159; Golinski, 1998, 162-170).

Tenemos el caso sintomático de la UCLA, en cuyo departamento de historia se creó a principios de los '90 un Center for the Cultural History of Science que rápidamente fue rebautizado como Center for Cultural Studies of Science, Technology, and Medicine. Si echamos un vistazo a los programas de doctorado de historia de la ciencia en todo el mundo, veremos que muchos incluyen asignaturas bajo sendas fórmulas.

Respecto a los estudios culturales, no parece exagerado afirmar que son un cajón de sastre en todo el mundo. Originalmente remiten a Birmingham, donde allá por 1964 se creó el Center for Contemporary Cultural Studies, dedicado al estudio simultáneo del cine y los media, los museos, la comunicación y la teoría social, un tipo de estudios deudores de la Escuela de Frankfurt con un acento politico determinado. Por el contrario, los actuales estudios culturales en Estados Unidos están más relacionados con la crítica literaria, los estudios de género y las culturas marginales.

La historia cultural, a su vez, también comprende temas y trabajos muy dispares. Por un lado remite a cierta tradición germánica o centroeuropea. Pensamos en Burkhardt, naturalmente, en el propio Norbert Elias, pero también en Huizinga, incluso en Cassirer. En Francia, por ejemplo, se encuentran ejemplos muy diversos, desde los más liga- dos a la antigua historia de las mentalidades (¿acaso la Historia del miedo en Occidente de Delumeau no es una historia cultural?), hasta la nueva historia del libro y la cultura escrita (Chartier), pasando por la sombra alargada de Foucault y el postestructuralismo.

La historia cultural en el mundo anglosajón, por su parte, es otro repertorio de tradiciones que guardan relación unas con la historia del arte (con Panofsky, Gombrich y el Instituto Warburg), otras con los estudios sobre cultura popular (como los del propio Burke e incluso E.P. Thompson) o con los trabajos del americano Robert Darnton sobre el episodio de la matanza de los gatos en la época de la Revolución francesa o el negocio editorial de la Enciclopedia, por citar algunos referentes conocidos.

Precisamente y a propósito de Darnton, la historia cultural debe mucho al giro antropológico de las ciencias sociales y en concreto a la antropología simbólica. Tras el estructuralismo, la obra de Clifford Geertz, La interpretación de las culturas (1973), marcó un hito en este sentido y sigue siendo un referente obligado. La descripción densa con que retrató las famosas peleas de gallos en Bali tuvo la virtud de desvelar el juego profundo y la pluralidad de significados que se movilizaban tras algo aparentemente trivial. La acción social pasaba a ser vista como un discurso al que el etnógrafo -o cualquier estudioso de la conducta humanase enfrentaba con el objeto de interpretar sus significados. Los significados, los ritos y los símbolos se introducían así en la agenda de todos los estudiosos e historiadores de la cultura. El propio Geertz reconocía que su punto de vista nacía del interés creciente que, dentro de la antropología, pero también en el resto de las ciencias sociales, había logrado despertar el papel de las formas simbólicas en la vida humana ${ }^{6}$.

Cierto que ese interés se había desatado ya desde el estructuralismo y la obra de Lévi-Strauss, pero el acento científico, explicativo, se trasladó hacia una orientación más weberiana, más autoconsciente de la inconmensurabilidad de la acción humana y más próxima al sentir de las ¿cómo llamarlas? ¿Humanidades, ciencias sociales? Sucede, sencillamente, que algunos historiadores siempre se reconocieron mejor (nos hemos reconocido mejor, para qué ocultarlo) en quienes -como Geertz-defendieron que su tarea o la nuestra, más que una ciencia experimental en busca de leyes, era una ciencia interpretativa en busca 
de significado. Esta mirada nos resulta más ajustada a la naturaleza de nuestro objeto de estudio, esto es y precisamente: más cultural.

No sería difícil detectar la influencia de algunos de estos ejemplos en la historia cultural de la ciencia, en absoluto un campo bien definido y delimitado como estamos viendo, pero sí al menos una perspectiva o una manera de acercarse al pasado de la ciencia marcada por una serie de estrategias, preguntas, puntos de atención y tópicos recurrentes. Veamos algunos.

\section{Prácticas y Representaciones}

Quizás sean los dos términos más repetidos en los últimos años: prácticas y representaciones. La historia cultural de la ciencia los emplea por razones fáciles de explicar.

La noción de práctica viene a recordar algo tan elemental como que los científicos no sólo hablan, no sólo dicen que hacen cosas, sino que también las hacen. Las "prácticas experimentales" o las "prácticas médicas", las "prácticas de la historia natural" o las "prácticas de observación astronómicas", cualquier escenario se ha transformado en un campo idóneo para estudiar el comportamiento de los científicos y las formas de producir conocimiento. El libro de Shapin y Schaffer, El Leviatán y la bomba de aire (1985), sigue ocupando un lugar destacado en este capitulo. El extrañamiento de la mirada antropológica sobre lo que hacian Boyle y el resto de los honorables caballeros en el laboratorio, así como el desplazamiento del interés desde las palabras y los textos hacia las reglas sociales que rigen las relaciones en las comunidades y el manejo de los instrumentos, convirtieron la vida experimental en un espacio abonado para indagar cuánto de artificial hay en la elaboración del conocimiento natural.

La ciencia moderna, en cierto sentido, abandonaba aquel aire estilizado, abstracto, evanescente, para transformarse en una actividad sometida a una serie de contingencias sociales y materiales. Y también dejaba de estar fijada a la palabra escrita y la teoría. Dejaba de ser exclusivamente una historia textual o libresca para convertirse también en la historia de cómo se realizó tal o cual experimento y cómo se replicó en otro espacio o en otro momento, bajo otras circunstancias.
Las comunidades científicas, sus reuniones y actividades, podían ser tratadas con la mirada etnográfica de quien trataba de descifrar la conducta significativa -pongamos por caso- de una tribu en la Polinesia. Frente a la manera wigh (presentista) de abordar la tradición científica occidental, esa manera convencional de rescatar y proyectarse sobre los antecedentes de nuestras formas actuales de conocimiento, la historia cultural de la ciencia ha tratado de acogerse a un lema antropológico que Shapin y Schaffer ejercieron como pocos: play the stranger.

El caso de los viajes también es un buen ejemplo. Siempre se ha sabido que buena parte de la geografía, la cartografía, la historia natural e incluso la astronomía moderna se habian nutrido de las observaciones y noticias recopiladas por los viajeros y los exploradores. Sin embargo, la antigua historia de la ciencia, centrada en los resultados y no en cómo se habian generado, tendía a silenciarlos 0 al menos no los situaba en el centro del relato. Hoy día, la proliferación de estudios sobre viajes y prácticas viajeras en el seno de la nueva historia cultural de la ciencia no sólo es proverbial, sino también sintomática (Elsner y Rubies, 1999). Unos agentes y una actividad antes considerados menores resultan ahora de gran interés. En realidad, toda la actividad científica tiende a ser vista hoy como una actividad que se comunica y se desplaza: la circulación del conocimiento ha devenido en uno de los grandes tópicos de la historia de la ciencia actual (Secord, 2004).

Otro tanto podría decirse de las prácticas sociales de los científicos o de la propia actividad científica como práctica social, cuyo nacimiento en la temprana Edad Moderna ha sido dibujado en el contexto de las relaciones de corte y las de mecenazgo, como es el caso del libro de Mario Biagioli, Galileo Courtier. The practice of science in the culture of Absolutism (1994).

Así que el acento se ha ido desplazando desde el qué al cómo, siendo éste uno de los rasgos más distintivos de una nueva historia de la ciencia que, como vemos, tiene tanto de cultural como de social. Hoy día los historiadores ya no se preocupan tanto de los contenidos de la ciencia como de las formas con que los obtuvieron quienes los crearon, constatando por otra parte la estrecha relación - por no decir la fuerte dependencia- que hay entre lo uno y lo otro. 
Ligado en cierta manera a esta preocupación por las formas de producción de conocimiento, aunque también motivado por el giro lingüistico y la influencia de la semiótica y del Ilamado literary criticism, tenemos el segundo término, representaciones, un término verdaderamente polisémico y polifónico. La historia de la ciencia también se ha visto anegada por este concepto tan cargado desde la epistemología y la filosofía del lenguaje. Su sola mención pone sobre la mesa un hecho notable, la cercanía entre la actividad científica, la pintura, la poesía, la narrativa de ficción, el teatro y en general cualquier actividad humana impregnada por la poética y la retórica.

Se han multiplicado los estudios que subrayan cómo el lenguaje y el discurso científico, lejos de mimetizar los fenómenos naturales estudiados, lejos de copiarlos asépticamente, los fabrican o si se prefiere los reconstruyen con el ánimo de persuadir o convencer a una comunidad (de expertos o legos, según el caso). Es decir, el lenguaje científico hace cosas (interviene sobre la realidad) y está dotado de los mismos aspectos comunicativos que cualquier otro lenguaje. Es un lenguaje, en este sentido, poético y retórico.

Esto explica que se hayan estudiado las técnicas literarias de comunicación científica, la retórica de la objetividad, la prosa o la estructura narrativa de los escritos científicos. Palabras como argumentación o metáfora son hoy dia comunes en los estudios culturales de la ciencia. Precisamente y a modo de ejemplo, podemos citar el libro Darwin's Metaphor: Nature's Place in Victorian Culture (1985), un texto que trató de superar las divisiones disciplinares actuales para estudiar el darwinismo dentro de un amplio sistema de valores y referencias culturales en la época victoriana. No es casual que su autor, Robert M. Young, sea el editor de la revista británica Science as culture, una de las publicaciones periódicas donde tienen cabida trabajos de esta nueva orientación. Tampoco es casual que otra revista se llame precisamente Representations, editada en la UCLA. Pese a no estar centrada en historia de la ciencia, resulta ilustrativo ver cómo entre sus tópicos se encuentran mezclados algunos de los más recurrentes dentro de los estudios culturales y la historia cultural: junto a los estudios de ciencia y tecnología, tenemos los de género, cuerpo y sexualidad, raza y etnicidad, historia y memoria, narrativa y poética, cultura visual, etc.

\section{Cultura visual y material}

El énfasis en las formas de producción y comunicación de conocimiento, en sus medios de representación, así como la fuerte conciencia de que la ciencia no sólo se dice -se enuncia- sino que fundamentalmente se hace, ha motivado una apreciable deriva hacia las dimensiones visuales y materiales de la ciencia. En realidad, la deriva podría ampliarse hacia sus aspectos físicos, tangibles o visibles. Forma parte de la reacción comentada arriba contra la ciencia entendida como una abstracción, un producto inmaterial procedente del intelecto.

Las manos y los ojos, los soportes materiales y las propias cosas han entrado en escena para los historiadores de la ciencia, de la misma forma que lo han hecho otros elementos relacionados con lo físico y lo sensible (así, el cuerpo, el espacio, la arquitectura y todo lo vinculado a los lugares donde se produce la ciencia, puesto que la propia noción de cultura tiende a resaltar lo local frente a lo universal).

Respecto a lo visual, qué duda cabe que vivimos una era de expansión del mundo de la imagen (Rodríguez de la Flor se refería a ello como una "hiperplasia de la imagen"). Los estudios visuales han penetrado con fuerza en la historiografía y en términos generales podemos decir que hoy día los historiadores han dejado de considerar las imágenes como ilustraciones, para tratarlas como fuentes, susceptibles de ser interrogadas, leídas e interpretadas como si fueran un texto.

En historia de la ciencia moderna se citan además otras circunstancias que han contribuido a revalorizar la imagen, la vista y las artes visuales. Al fin y al cabo, como afirma Norton Wise en la introducción de un monográfico de la revista Isis dedicado a la ciencia y la cultura visual, "gran parte de la historia de la ciencia puede ser escrita en términos de cómo se hicieron visibles cosas nuevas"7.

Tenemos la propia importancia que los partidarios de la filosofía natural moderna concedieron a los hechos sensibles sobre la autoridad de la palabra escrita. El contacto directo con los fenómenos naturales frente al saber textual -el triunfo del libro de la naturaleza frente al Libro- condujo a exaltar la cultura visual. Se inventaron y perfeccionaron nuevos instrumentos y métodos de observación. No casualmente, una de las primeras academias científicas se 
Ilamó los Lincei, una elección que nos recuerda el papel de la agudeza visual en los tiempos fundacionales de la nueva ciencia. Se generalizó la idea de que las imágenes representaban las cosas de manera más fidedigna que el lenguaje y el discurso. Recordemos la cruzada de los modernos contra la retórica escolástica y el "ruido del mundo". A falta de la presencia real de un objeto o un fenómeno, se llegó al acuerdo de que las imágenes los sustituian mejor que las palabras. Merecian mayor crédito, tenían un estatus epistemológico de mayor rango. Desde entonces, la alianza entre iconografía y verdad se convirtió en un artículo de fe compartido por los partidarios de la ciencia moderna.

La relación entre ciencia y arte es mucho más acusada de lo que nuestra economía binaria está dispuesta a admitir. Si pensamos en lo que supuso la revolución de la pintura en el Renacimiento, la alianza entre el dibujo y los tratados de medicina, botánica e historia natural, no tardamos en apreciar la importancia de lo artesanal y lo artificial en la confección del conocimiento, ese dios otrora incorpóreo que sólo desde tiempos recientes estamos aprendiendo a dotar de forma, color, peso y medida, en una palabra, a materializarlo.

¿Y qué decir de la estampa y el grabado? El mecanismo de reproducción de la imagen ideado a finales del siglo XV fue tan decisivo en su día para la implantación y la expansión de la ciencia moderna, como luego ha sido ocultado por la historiografía tradicional de la Revolución científica, centrada en la imprenta de tipos móviles, en la reproducción de la palabra escrita y en su producto más característico, el libro. Se trata de un hecho muy sintomático. De nuevo tenemos otra versión del enfrentamiento ya comentado: la antigua historia de la ciencia se ocupaba de las ideas y la palabra escrita, frente a la nueva historia cultural de la ciencia, más interesada por las prácticas y las imágenes.

Son muchos los estudios que transitan entre la ciencia y el arte, estableciendo puentes y recordándonos el indisoluble vínculo que hay entre lo que pensamos, hacemos y vemos, tres operaciones tan conectadas como lo están la vista, las manos y el cerebro. Podemos mencionar en este capitulo la dilatada obra de Martin Kemp, quien lleva una vida trabajando en esta dirección, el volumen colectivo C.A. Jones y P. Gallison (ed.) Picturing Science, Producing Art (1998), o el citado monográfico de la revista Isis sobre ciencia y cultura visual (Isis, 2006, 97).
Por último, es evidente que dicha orientación visual, iconográfica e incluso iconológica de los estudios sobre el pasado de la ciencia ha discurrido en paralelo con la revalorización de la cultura material. Si nos preocupa cómo se obtiene el conocimiento, nada más normal que nos interese con qué procedimientos y medios materiales se obtiene. Esto explica el lugar central que han adquirido los instrumentos en la nueva historia de la ciencia. Los instrumentos no son ya sólo "teoremas rectificados", como queria Bachelard, sino que han pasado a soportar toda una trama de ideas, prácticas, negocios y relaciones sociales que forman parte de la actividad cientifica. La construcción, venta y difusión del instrumental científico, así como su empleo y el conjunto de reglas no escritas que comporta éste para que las observaciones o los experimentos puedan ser replicados, forman parte de la literatura común hoy día en historia de la ciencia.

Se escriben artículos y libros sobre la historia cultural del barómetro o el microscopio. Hemos aprendido detalles decisivos sobre los prismas con que Newton realizó el experimento crucial para descomponer la luz y demostrar su teoría del color. La historia cultural de la ciencia tiene en la historia cultural de la tecnología más que un apéndice o un derivado.

Igualmente, los historiadores de la medicina estudian los modelos anatómicos de cera; los de la biología y la geología los fósiles y su comercio a través de las redes científicas y diplomáticas del siglo XIX. Se han multiplicado los estudios sobre coleccionismo y repositorios de objetos y productos naturales en gabinetes de curiosidades y museos de historia natural. Al igual que Appadurai reivindicaba una historia social de las cosas, los historiadores de la ciencia hemos acabado por trazar biografías de objetos científicos, haciendo hablar a esos spechless objects, testigos antes mudos donde ahora se precipitan y proyectan relatos inéditos, discursos reveladores de los propósitos y las condiciones con que fueron fabricados o adquiridos, puestos en circulación o exhibidos. En la introducción de uno de los textos que sirve para ilustrar este apartado, Things that talk. Objects lessons form Art and Science (2004), Lorraine Daston, su editora, reconocia que su "colección de ensayos afronta y da por hecha la paradoja de que las cosas son materiales y a la vez están dotadas de significado. Asumimos que la materia tiene significado y viceversa"8. 


\section{LA CIENCIA COMO CULTURA}

Bien mirado, es una afirmación que recoge los dos aspectos quizás más característicos de la historia cultural de la ciencia, lo material y lo simbólico. La ciencia nos parece hoy una actividad por una parte más tangible, más física, más cercana a un bien de consumo o un producto que circula en el espacio y con el que se comercia; y por otra, se nos antoja como una práctica profundamente significativa de la conducta humana, una actividad donde se plasman y hacen visibles las estrechas relaciones entre orden natural y orden social.

En lugar de estudiar la ciencia en la cultura, la ciencia es vista como cultura, una distinción que puede parecer escolástica, pero que revela concepciones muy diferentes de lo que es la ciencia y también de la propia tarea del historiador. Respecto a la primera, una concepción cultural entiende la ciencia como una realidad diversa y mutable (las culturas son diversas y mutables), diferente a la antigua concepción universalista y permanente del conocimiento.

Respecto al trabajo de los historiadores culturales de la ciencia, viene definido por su visión integradora del campo de visión y actuación de un historiador. Un historiador cultural de la ciencia, por ejemplo, no se contenta con saber cuándo fue traducido el tratado de Óptica de Newton o cuando llegó a tal biblioteca o a cual ciudad. Tampoco induce de sendos hechos la arribada del newtonismo. Un historiador cultural de la ciencia se pregunta cómo, cuándo, de qué forma y con qué resultados se replicaron sus experimentos; se interroga sobre el significado cultural del newtonismo; rastrea si al ser trasladado fuera de Inglaterra mantuvo las implicaciones antitrinitarias y latitudinarias que había tenido en el contexto de los debates religiosos y políticos en la Inglaterra de la Restauración o si por el contrario adoptó otras nuevas; permanece atento a las manifestaciones artísticas o poéticas que originó; se pregunta si su adopción llevó aparejada la de otras formas de newtonismo filosófico o social (Locke, el lenguaje de la economía política, etc.). Su bateria de preguntas es amplia.

También son variadas las fuentes con las que trabaja: documentos, materiales, imágenes, espacios urbanos, etc. Lorraine Daston habla del tratamiento ecuménico de las fuentes como el rasgo distintivo de la historia cultural de la ciencia ${ }^{9}$. Un historiador del electromagnetismo, en efecto, debe entrar en contacto con las ecuaciones de Maxwell, pero también con los diseños y planos del laboratorio que dirigió, los instrumentos que se conservan de entonces, las técnicas pedagógicas que empleó con sus estudiantes en Cambridge o las propias relaciones que había entre competiciones matemáticas y deportivas en la universidad.

La tarea, en consecuencia, se ha diversificado notablemente y se ha vuelto más penosa en cierto sentido. La historia cultural de la ciencia que se escribe hoy es una práctica sofisticada que ha logrado remodelar la imagen que teníamos de la actividad científica y que se ha convertido en una referencia imprescindible dentro de la historia cultural, como lo muestra la atención que le prestan algunos historiadores destacados que no procedían de la historia de la ciencia y que han acabado por incorporar sus tópicos y preocupaciones en su agenda y en sus investigaciones (Darnton, Chartier, el propio Burke).

La antigua visión textual, ideal y universal del conocimiento científico ha devenido en un conjunto de miradas más fragmentarias sobre las prácticas, los significados, la cultura visual y material de la actividad científica.

Por descontado, como ocurre cuando las etiquetas responden a modismos de época muy generalizados, junto al uso encontramos el abuso, una banalización fruto de una moda que, como todas, tiene o puede tener algo de impostura. ¿Quién no se acuerda de cierta historiografía marxista de los años '70 que en realidad se limitaba a citar el materialismo histórico sin haber leído a Engles, a Feuberbach o a Hegel? No todo lo que se presenta como historia cultural de la ciencia lo es. Y como sucede con cualquier orientación, dentro de ésta hay trabajos de calidad desigual. Sólo el tiempo juzgará qué aportaciones han sido relevantes, pues una de las peculiaridades del trabajo historiográfico bien hecho es que perdura aunque sea superado o pase de moda, lo que provoca que ciertos trabajos antiguos sigan diciendo y enseñando tanto, mientras que otros, muy actuales o muy aggiornados, sean prescindibles. Al fin y al cabo, como a los científicos o a los políticos, a los historiadores conviene juzgarlos por lo que hacen y dan, más que por lo que prometen o teorizan. La historiografía, como género narrativo, muestra más de lo que dice. En realidad, sólo puede llegar a decir cosas -como quería Aristóteles- poniéndolas delante de los ojos. 
1 Este texto tuvo su origen en mi participación en la mesa redonda sobre historia cultural de la ciencia, dentro del seminario en homenaje a Peter Burke, una mesa en la que los organizadores nos propusieron como tema a discutir, precisamente: $A$ double bind? Perspectives on a Discipline.

2 Como los Principia de Newton o el Quijote de Cervantes, Las dos culturas de Snow es un texto más citado que leído. Nos permitimos recomendar la cuidada edición de Cambridge University Press, que incluye las dos partes (la Rede Lecture de 1959 y The two cultures: a second look, 1963), introducidas por un extenso ensayo de Stefan Collini: Snow, 1998.

3 Gallison, 2008, 112.

4 Para una visión panorámica de esta tradición historiográfica, véase el monográfico que publicó la revista Isis con ocasión del 75 aniversario de la fundación de la Sociedad de Historia de la Ciencia (Isis, 1999). Para un público más ancho, Shapin, 1996; Dear, 2001.

5 Dear, 1995, 159.

6 Geertz, 1973, 29.

7 Wise, 2006, 75.

8 Daston, 2004, 17.

9 Daston, 2002, 48.

\section{BIBLIOGRAFÍA}

Biagioli, M. (1994): Galileo, Courtier. The practice of Science in the Culture of Absolutism, Chicago, The University of Chicago Press (hay trad. castellano: Katz, 2008).

Burke, P. (2002): Historia social del conocimiento, Madrid, Paidós.

Recibido: 1 de diciembre de 2008

Aceptado: 1 de junio de 2009

Daston, L. (2002): "Knowledge and Science: the new history of science", en He- rrero M. y Scholz, J.-M., Las ciencias sociales y la modernización, Madrid, Real Academia de Ciencias Morales y Políticas, pp. 33-53.

Daston, L. (ed.) (2004): Things that talk. Objects lessons from Art and Science, New York, Zone Books.

Dear, P. (1995): "Cultural history of Science: An Overview with Reflections", Science, Technology \& Human Values, vol. 20, n. ${ }^{\circ}$, pp. 150-170.

Dear, P. (2001): Revolutionizing the Sciences, London: Palgrave (hay trad. al castellano: Marcial Pons, 2007).

Elsner, J. and Rubies, J. P. (ed.) (1999): Voyages and Visions: Towards a Cultural History of Travel, London, Reaktion Books.

Gallison, P. (2008): "Ten problems in History and Philosofphy of Science", Isis, vol. 99, pp. 111-124.

Geertz, C. (1973): The interpretation of cultures, New York, Basic Books.

Golinski, J. (1998): Making natural knowledge. Constructivism and the history of science, Cambridge, Cambridge University Press.

Isis, 1990, vol. 90. Suppl: Catching up with the vision.

Secord, J. (2004): "Knowledge in transit", Isis, vol. 95, pp. 654-672.

Shapin, S. and Schaffer, S. (1985): Leviathan and the Air-Pump. Hobbes, Boyle and the Experimental Life, Princeton, Princeton University Press (hay trad. castellano: Quilmes, 2006).

Shapin, S. (1996): The Scientific RevoIution, Chicago, Chicago University Press (hay trad. castellano: Paidós, 2000).

Smith, P. (2006): "Art, Science, and Visual Culture in Early Modern Europe", Isis, vol. 97, pp. 83-100.

Snow, C. P. (1998): The two cultures, Cambridge, Cambridge University Press.
Wise, N. (2006): "Making visible", Isis, vol. 97, pp. 75-82. 